\title{
HERBIVORE DEFENCE COMPOUNDS OCCUR IN POLLEN AND REDUCE BUMBLEBEE COLONY FITNESS.
}

\author{
SARAH E. J. ARNOLD ${ }^{* 1}$, M. EDUARDO PERALTA IDROVO ${ }^{2}$, LUIS J. LOMAS ARIAS ${ }^{2}$, \\ STEVEN R. BELMAIN ${ }^{1} \&$ PHILIP C. STEVENSON ${ }^{1,3}$
}

${ }^{1}$ Natural Resources Institute, University of Greenwich, Chatham Maritime, ME4 4TB, UK
${ }^{2}$ Instituto Nacional Autónomo de Investigaciones Agropecuarias, Quito, Ecuador
${ }^{3}$ Royal Botanic Gardens, Kew, Richmond, TW9 3AB, UK

*Author for correspondence: s.e.j.arnold@ greenwich.ac.uk

Keywords: natural resistance; lupin; lupanine; pollination; Bombus terrestris

\begin{abstract}
Herbivory defence chemicals in plants can affect higher trophic levels such as predators and parasitoids, but the impact on pollinators has been overlooked. We show that defensive plant chemicals can damage pollinator fitness when expressed in pollen. Crop lupins (Lupinus species from Europe and South America) accumulate toxic quinolizidine alkaloids in vegetative tissues, conferring resistance to herbivorous pests such as aphids. We identified the alkaloid lupanine and its derivatives in lupin pollen, and then provided this compound at ecologically-relevant concentrations to queenless microcolonies of bumblebees (Bombus terrestris) in their pollen to determine how foraging on these crops may impact bee colony health and fitness. Fewer males were produced by microcolonies provided with lupanine-treated pollen and they were significantly smaller than controls. This impact on males was not linked to preference as workers willingly fed lupanine-treated pollen to larvae, even though it was deleterious to colony health. Agricultural systems comprising large monocultures of crops bred for herbivore resistance can expose generalist pollinators to deleterious levels of plant compounds, and the broader environmental impacts of crop resistance must thus be considered.
\end{abstract}

\section{INTRODUCTION}

Anti-herbivory compounds are diverse and widespread in plants (Bennett and Wallsgrove 1994). They use toxic and antifeedant effects to deter herbivorous animals, particularly invertebrates, from consuming plant tissues, and as such offer defence against insect and non-insect pest species. Antiherbivory compounds, including alkaloids (e.g. caffeine, nicotine) and glucosinloates (Bennett and Wallsgrove 1994), are ordinarily sampled from vegetative tissue, where they protect leaves, roots and stems from herbivorous insects. However, they can also occur in pollen or nectar, exposing foraging pollinators to them (Adler 2000). Pollinators, as consumers of plant material, are also a type of herbivore, but the consequences for pollinators of ingesting pollen and nectar containing defensive chemicals remain incompletely examined.

The genus Lupinus includes South American and European crop species such as $L$. mutabilis, L. albus, L. luteus and L. angustifolius (Williams 1987). These plants harbour a number of resistance compounds to protect from insect attack, particularly $D$-lupanine and its derivatives (comprising up to 3\% of seed tissue by weight (Hatzold et al. 1983)). Other alkaloid compounds present in various plant species are harmful to adult bees (Apis, Bombus) when administered in artificial nectar (Detzel and Wink 1993). Since $D$-lupanine is toxic and repellent to insects (Kordan et al. 2012) it could similarly have negative effects on larval or adult bees, at individual, colony or population level. 
Promotion of natural resistance mechanisms to protect crop plants from pests is seen as a particularly desirable response to the current pressure to reduce insecticide use, given the adverse effects of synthetic pesticides on beneficial insects (Bryden et al. 2013). It is therefore likely that resistance compounds in crops will become more common in future and that pollinators will encounter them more frequently.

In this study, we tested whether the presence of a resistance compound, $D$-lupanine, at levels equivalent to that detected in the pollen of Lupinus sp., has negative effects on fitness parameters (production and size of sexual offspring) in the generalist bumblebee Bombus terrestris L.

\section{METHODS AND RESULTS}

Pollen from the crop lupin species L. mutabilis was collected both from its native range in Ecuador $(N=>100$ plants) and from the cultivar cruckshankii grown from purchased seeds (B\&T World Seeds, Aigues-Vives, France) ( $N=2$ plants), under glass in the UK. Pollen was collected by gently easing back the petals of the keel to expose anthers and then tapping pollen into an Eppendorf tube. The pollen (10 mg each time) was sonicated for $10 \mathrm{~min}$ in $1 \mathrm{ml}$ methanol and extracted for a further $24 \mathrm{~h}$ in an Eppendorf tube, centrifuged at 12,000 rpm for $5 \mathrm{~min}$ and the supernatant analysed by LC-MS using a Waters Alliance system with a ZQ LC-MS detector on a Phenomenex Luna C18(2) column $(150 \times 43.0 \mathrm{~mm}$ i.d., $3 \mu \mathrm{m}$ particle size $)$ operating under gradient conditions, with $\mathrm{A}=\mathrm{MeOH}, \mathrm{B}=\mathrm{H}_{2} \mathrm{O}, \mathrm{C}=1 \% \mathrm{HCO}_{2} \mathrm{H}$ in $\mathrm{MeCN} ; \mathrm{A}=0 \%, \mathrm{~B}=90 \%$ at $\mathrm{t}=0 \mathrm{~min} ; \mathrm{A}$ $=90 \%, \mathrm{~B}=0 \%$ at $\mathrm{t}=20 \mathrm{~min} ; \mathrm{A}=90 \%, \mathrm{~B}=0 \%$ at $\mathrm{t}=30 \mathrm{~min} ; \mathrm{A}=0 \%, \mathrm{~B}=90 \%$ at $\mathrm{t}=31 \mathrm{~min}$; column temperature $30^{\circ} \mathrm{C}$ and flow rate of $0.5 \mathrm{ml} / \mathrm{min}$. Lupanine was detected after $2.2 \mathrm{~min}$ in the Total Ion Chromatogram (TIC) and quantified against a calibration curve of lupanine (Sigma Aldrich, Dorset, UK) by integration of single ion chromatograms of the $[\mathrm{M}+\mathrm{H}]^{+}$ion with $\mathrm{m} / z 249.1$. HREIMS measurements were made using a Thermo LTQ-Orbitrap XL mass spectrometer. Sample introduction was via a Thermo Accela LC system performing chromatographic separation of $5 \mu 1$ injections on a Phenomenex Luna C18(2) column (150 x $3.0 \mathrm{~mm}$ id, $3 \mu \mathrm{m}$ particle size) with a linear mobile phase gradient of $10-100 \%$ aqueous $\mathrm{MeOH}$ containing $0.1 \%$ formic acid over $20 \mathrm{~min}$. Spectra were recorded in positive modes at 30,000 resolution and molecular formulae calculated from accurate mass of $[\mathrm{M}+\mathrm{H}]^{+}$and $[\mathrm{M}+\mathrm{Na}]^{+}$.

Quinolizidine alkaloids (with $D$-lupanine the major alkaloid component) were detected in pollen of both cultivars. D-lupanine occurred in L. mutabilis at a concentration of $2.0 \mathrm{mg} / \mathrm{g}$ in pollen (around one-ninth of the prevalence found in seeds (Hatzold et al. 1983)). Other lupanine derivatives were tentatively identified based on their HREIMS spectrum, elution and known occurrence in L. mutabilis from literature. These included 13-O-hydroxylupanine at $1.72 \mathrm{~min},(\mathrm{~m} / \mathrm{z}$ $265.1915[\mathrm{M}+\mathrm{H}]^{+}$calc. for $\mathrm{C}_{15} \mathrm{H}_{25} \mathrm{O}_{2} \mathrm{~N}_{2}$ 265.1911), 4- $O$-hydroxy-13-O-angeloyloxylupanine at 4.81 $\min \left(\mathrm{m} / \mathrm{z} 363.2284[\mathrm{M}+\mathrm{H}]^{+}\right.$calc. for $\mathrm{C}_{20} \mathrm{H}_{31} \mathrm{O}_{4} \mathrm{~N}_{2}$ 363.2278), 13-O-angeloyloxylupanine at 5.84 min. $\left(\mathrm{m} / z, 347.2333[\mathrm{M}+\mathrm{H}]^{+}\right.$calc. for $\mathrm{C}_{20} \mathrm{H}_{31} \mathrm{O}_{3} \mathrm{~N}_{2}$ 347.2329) and 13-O-tigloyloxylupanine at 7.62 min. $\left(m / z 347.2340[\mathrm{M}+\mathrm{H}]^{+}\right.$calc. for $\mathrm{C}_{20} \mathrm{H}_{31} \mathrm{O}_{3} \mathrm{~N}_{2}$ 347.2329), all previously reported in L. mutabilis (Hatzold et al. 1983). D-lupanine and other quinolizidine alkaloids were also detected on the surface of the nectary (via analysis of nectary washes, in which $10 \mu \mathrm{l}$ of water was pipetted into the nectary of a bagged flower, left overnight and collected the next morning before analysis as described above for pollen). The occurrence of alkaloids in the nectary would enable workers to come into contact with $D$-lupanine when foraging

Four colonies of bumblebees (B. terrestris; Syngenta Bioline, Netherlands) were each divided into four queenless microcolonies. We have found that split colonies tend to be more successful than worker-founded microcolonies not provided with brood (e.g. as used by Tasei et al. (2000)) and produce new brood more quickly. Each microcolony was randomly allocated to one of the four $D$-lupanine concentration treatments. Workers (mean of 15 per microcolony) and developing brood from each parent colony were distributed evenly between the microcolonies, housed in four wooden nestboxes (consisting of a front antechamber and rear nesting chamber). Bees were provided with ad libitum sugar syrup (Invertabee, Paynes Bee Farm, Hassocks, UK) throughout the assay and kept in $12: 12 \mathrm{D}: \mathrm{L}$ conditions at $25^{\circ} \mathrm{C}$ and ambient humidity. One to two 
times per week depending on consumption rates, $2.0 \mathrm{~g}$ of mixed wildflower pollen (Syngenta Fargro, Little Clacton, UK and Paynes Bee Farm) per microcolony was provided to bees in a $28 \mathrm{ml}$ plastic dish in the antechamber. This was mixed with $D$-lupanine at $0.0 \mathrm{mg} / \mathrm{g}$ (control), $0.2 \mathrm{mg} / \mathrm{g}$, $1.0 \mathrm{mg} / \mathrm{g}$ or $2.0 \mathrm{mg} / \mathrm{g}$ pollen, dissolved in $0.5 \mathrm{ml}$ acetone in each case; the latter is equivalent to the concentration of lupanine in L. mutabilis pollen. Pollen treated as above was the only pollen provided to bees; the mass of pollen before presentation to the bees and after the dish was removed from the colony was measured in order to calculate consumption. Thorax widths and masses of all callow male bees emerging from the microcolonies were recorded to the nearest $0.01 \mathrm{~mm}$ and 0.002 $\mathrm{g}$ respectively, after euthanasia by freezing. The assay was run until fewer than two workers were left alive in at least one microcolony from a single parent colony, at which point the assay was terminated for all four microcolonies in that replicate. The last male to be collected emerged 47 days after the assay began.

A mean of $11 \pm 6$ males were produced per colony; significantly more males were produced by the control microcolonies receiving pollen without $D$-lupanine $\left(\chi^{2}\right.$ test, $\left.\chi_{9}^{2}=24.0, p=0.004\right)$ (Figure 1a). All microcolonies readily collected and consumed the pollen (treated or control) provided to them during the course of the experiment, at statistically indistinguishable rates (Control mean \pm s.e.m.: $5.43 \pm 2.39 \mathrm{~g}, 0.2 \mathrm{mg} / \mathrm{g}$ treatment: $4.89 \pm 1.37 \mathrm{~g} ; 1.0 \mathrm{mg} / \mathrm{g}$ treatment: $4.95 \pm$ $1.87 \mathrm{~g} ; 2.0 \mathrm{mg} / \mathrm{g}$ treatment: $4.42 \pm 1.36 \mathrm{~g})\left(\mathrm{GLM}, F_{3,9}=0.157, p=0.922\right)$, although pollen consumption did vary between parent colonies (GLM, $F_{3,9}=8.89, p=0.005$ ). The size (thorax width) of the males, an indicator of the colonies' fitness, decreased with increasing lupanine concentration in the pollen (General Linear Model (GLM): $F_{3}=4.165, p=0.014$ ) (Figure 1b). The originating parent colony affected response to the lupanine treatment (GLM: $F_{4}=3.698, p=0.015$ ). Similarly, mass (while potentially more variable if the bee fed recently or was frozen for a longer period) correlated highly with thorax width, and decreased with increasing lupanine concentration (GLM: $\left.F_{3}=3.62, \mathrm{p}=0.024\right)$ with parent colony (GLM: $F_{4}=3.750, p=0.014$ ) affecting response to treatment. There was no effect of lupanine concentration on workers' size, measured as thorax width (GLM: $\left.F_{3}=0.534, p=0.682\right)$.

\section{DISCUSSION}

As the reproductive output in the absence of gynes, males represent a bumblebee colony's fitness and deleterious effects of their food or environment on them could have severe consequences for the colony. Larger male bumblebees mate more quickly and frequently than small ones both in the presence and absence of competition from other males (Amin et al. 2013), indicating that small males may be both less competitive with other males and less attractive to gynes. Effects of $D$ lupanine in foraging material could, therefore, impact the next generation as well as the generation being exposed. Similarly to many assayed alkaloids, $D$-lupanine has exhibited other negative effects on insects; it inhibits larval development in Lepidoptera (Johnson and Bentley 1988), so it is feasible that comparative effects should be observed in Hymenoptera.

Plant secondary compounds are often produced to deter herbivores. However, one must consider that pollinators are also herbivores, and exposure to some secondary compounds in nectar affects adult pollinators (Wright et al. 2013), sometimes in similar ways to the effects of insecticide exposure via pollen or nectar (Bryden et al. 2013; Tasei et al. 2000). Few studies have examined the effect of naturally-occurring plant compounds in the larval food of pollinators, or determined how larval feeding may impact on offspring production or fitness, i.e. evaluating whether bees can be inadvertently poisoned by their food. We found that a secondary compound present in the pollen of some crop species can have negative effects on pollinators' fitness. This has major implications where bees provide pollination services to crops that depend upon chemically-based host plant resistance to reduce pest damage.

B. terrestris have poor taste acuity for plant toxins at natural concentrations (Tiedeken et al. 2014). While lupanine was deterrent to bees at high concentrations in an artificial nectar (pers. obs.), our microcolonies were not deterred from collecting pollen with ecologically-relevant lupanine concentrations and fed it to larvae, suggesting that lupanine-treated pollen is acceptable to 
bees when it is the only pollen available. This highlights a realistic risk of regular ingestion to this pollen in nature where Lupinus crop species are grown. Pollen of Lupinus spp. is readily accepted and collected by bumblebees in the Bombus: Bombus subgenus, sometimes in very large amounts (Williams 1987; Rasheed and Harder 1997), with high floral constancy exhibited; while $B$. terrestris is not native to South America, other Bombus species regularly visit L. mutabilis in its native range (Williams 1987). L. mutabilis grown in UK gardens is readily visited by generalist pollinators (pers. obs.). B. terrestris regularly visits other Lupinus crop and ornamental species (Bilgen \& Ozyigit 2001; Stout et al. 2002).

Furthermore, crop lupins have a long flowering period (Williams et al. 1990), so pollinators may be harvesting harmful pollen from Lupinus sp. for months, particularly as many common generalist bumblebee species have long nesting seasons and some are bivoltine (Ings et al. 2005). There is potential for overlapping phenology of bumblebee male production and lupin flowering periods; the acceptability of Lupinus pollen combined with the potentially long period of availability means the possibility of bumblebees feeding lupin pollen, where available, to their offspring is high - particularly where it is cultivated as a large-scale crop.

As illustrated here in a model crop, insect-resistant varieties of crops that rely on naturallyoccurring entomotoxic plant compounds have the potential to impact pollinators. Although these effects may be sub-lethal, they may nonetheless have subtle but important colony impacts, as implied by our data. This requires consideration in all insect-pollinated crops where insect resistance is a component of pest control. As crop lupins benefit from pollinator visits for optimal seed-set (Williams 1987), and as the seeds are the valuable product, it is imperative that adequate pollination is maintained and that pollinator populations remain healthy.

Acknowledgements - Funded by a University of Greenwich HEFCE (RAE) project and a grant jointly from BBSRC, DEFRA, NERC, the Scottish Government and the Wellcome Trust, under the Insect Pollinators Initiative BB/I000968/1. We thank Dr Claire Nicklin, Dudley Farman and Dr Geoff Kite for assistance, and Dr André Kessler and two anonymous referees for helpful comments on the manuscript.

\section{REFERENCES}

ADLER LS. 2000. The ecological significance of toxic nectar. Oikos 91(3):409-420.

AMIN MR, BUSSIÈRE LF, GOULSON D. 2013. Effects of male age and size on mating success in the bumblebee Bombus terrestris. J Insect Behav 25(4):362-374.

BENNETT RN, WALLSGROVE RM. 1994. Secondary metabolites in plant defence mechanisms. New Phyt 127(4):617-633.

BILGEN M, ÖZYIĞIT Y. 2001. Antalya ili Tekirova-phaselis beldesindeki Arı bitkilerinin belirlenmesi üzerine bir araştırma. 5th Turkish Field Plant Congress, Turkey, 565-567

BRYDEN J, GILL RJ, MITTON RAA, RAINE NE, JANSEN VAA. 2013. Chronic sublethal stress causes bee colony failure. Ecol Lett 16(12):1463-1469.

DETZEL A, WINK M. 1993. Attraction, deterrence or intoxication of bees (Apis mellifera) by plant allelochemicals. Chemoecol 4(1):8-18.

HATZOLD T, ELMADFA I, GROSS R, WINK M, HARTMANN T, WITTE L. 1983. Quinolizidine alkaloids in seeds of Lupinus mutabilis. J Agr Food Chem 31(5):934-938.

INGS TC, SCHIKORA J, CHITTKA L. 2005. Bumblebees, humble pollinators or assiduous invaders? A population comparison of foraging performance in Bombus terrestris. Oecologia 144(3):508-516.

JOHNSON ND, BENTLEY BL. 1988. Effects of dietary protein and lupine alkaloids on growth and survivorship of Spodoptera eridania. J Chem Ecol 14(5):1391-1403. 
KORDAN B, DANCEWICZ K, WRÓBLEWSKA A, GABRYŚ B. 2012. Intraspecific variation in alkaloid profile of four lupine species with implications for the pea aphid probing behaviour. Phytochem Lett 5(1):71-77.

RASHEED S, HARDER L. 1997. Economic motivation for plant species preferences of pollencollecting bumble bees. Ecol Entomol 22(2):209-219.

STOUT JC, KELLS AR, GOULSON D. 2002. Pollination of the invasive exotic shrub Lupinus arboreus (Fabaceae) by introduced bees in Tasmania. Biol Conserv 106:425-434.

TASEI J-N, LERIN J, RIPAULT G. 2000. Sub-lethal effects of imidacloprid on bumblebees, Bombus terrestris (Hymenoptera: Apidae), during a laboratory feeding test. Pest Manage Sci 56(9):784-788.

TIEDEKEN EJ, STOUT JC, STEVENSON PC, WRIGHT GA. 2014. Bumblebees are not deterred by ecologically relevant concentrations of nectar toxins. J Exp Biol In press.

WILLIAMS IH, MARTIN AP, FERGUSON AW, CLARK SJ. 1990. Effect of pollination on flower, pod and seed production in white lupin (Lupinus albus). J Agr Sci 115:67-73.

WILLIAMS IH. 1987. The pollination of lupins. International Bee Research Association. 10-16 p.

WRIGHT GA, BAKER DD, PALMER MJ, STABLER D, MUSTARD JA, POWER EF, BORLAND AM, STEVENSON PC. 2013. Caffeine in floral nectar enhances a pollinator's memory of reward. Science 339(6124):1202-1204.

Fig. 1 a) Production and b) size of males in tested microcolonies. Male production (mean \pm s.e.m.) and mean thorax widths ( \pm s.e.m.) of microcolonies receiving pollen containing $0.0,0.2,1.0$ or $2.0 \mathrm{mg} / \mathrm{g}$ lupanine. Control microcolonies produced more males $\left(\chi_{9}^{2}=24.0, p=0.004\right)$, while thorax width decreases with increasing lupanine concentration (GLM: $F_{3}=4.165, p=0.014, N=$ 41)
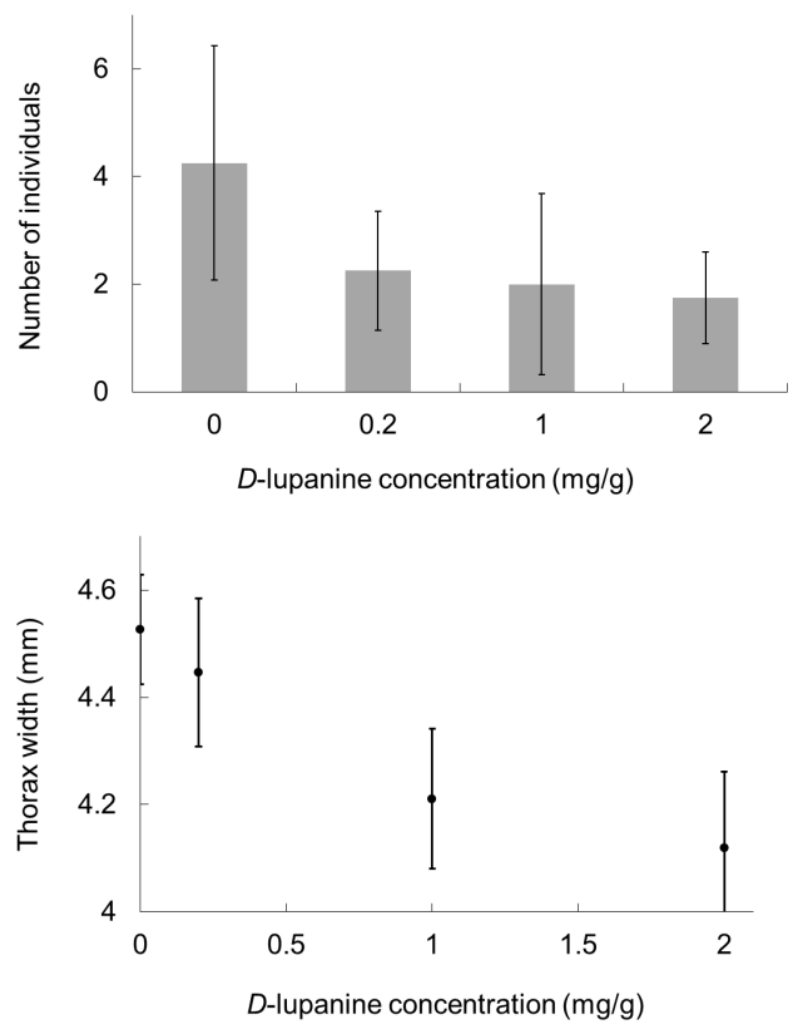